\title{
TRANSPORTE PÚBLICO CURITIBANO: histórias de designs pelo viés da teoria crítica da tecnologia
}

\author{
Suelen Christine Caviquiolo \\ Universidade Tecnológica Federal do Paraná (UTFPR) \\ su.cavi@gmail.com \\ Gilson Leandro Queluz \\ Universidade Tecnológica Federal do Paraná (UTFPR) \\ queluz@utfpr.edu.br
}

Resumo: Este trabalho discute, pelo viés da teoria crítica da tecnologia, a história do transporte público na cidade de Curitiba entre as décadas de 1960 e 1980. A partir do projeto e implantação do plano diretor, buscamos evidenciar como questões sociais foram traduzidas em questões técnicas que definiram os contornos mais visíveis do sistema de transporte. Em seguida, mostramos de que maneira a população que depende do transporte público reagiu ao design desse sistema que foi configurado em [por] um contexto político e econômico marcado pela tecnocracia da ditadura militar. Por fim, apontaremos possibilidades de designs alternativos que poderiam contemplar um sistema de transporte mais democrático.

Palavras-chave: Transporte Coletivo, Curitiba, Teoria Crítica da Tecnologia, História do Design em Curitiba.

\begin{abstract}
This paper discusses, through the critical theory of technology, the history of public transport in Curitiba between the 1960s and 1980s. From the design and implementation of the master plan, we seek to show how social issues were translated into technical issues which defined the more visible outlines of the transport system. Then, we show how the population which depends on public transportation reacted to the system's design that was set up in [for] a political and economic context marked by the technocracy of the military dictatorship. Finally, we will point out possibilities of alternative designs that could provide for a more democratic transportation system.
\end{abstract}

Keywords: Public Transport, Curitiba, Critical Theory of Technology, Curitiba's Design History. 


\section{INTRODUÇÃO}

O seguinte artigo aborda o design do transporte público na cidade de Curitiba, capital do Paraná, pelo viés da teoria crítica da tecnologia. Nele, discutimos a produção de códigos técnicos na história em relação com as disputas pelo controle dessa tecnologia urbana. O trabalho é parte de pesquisa de doutorado dedicada a pensar a construção social do transporte coletivo nessa cidade. Emprega como fontes, documentos públicos e reportagens jornalísticas encontrados nos acervos do Instituto de Pesquisa e Planejamento Urbano de Curitiba (Ippuc), Prefeitura Municipal de Curitiba e Biblioteca Pública do Paraná, somados à entrevista realizada com um arquiteto e urbanista que integrou o corpo técnico da prefeitura. $O$ texto também foi baseado em outras publicações sobre o planejamento urbano com abordagens da história e das ciências sociais.

A noção de código técnico que iremos apresentar e utilizar como apoio teórico e metodológico tem origem na teoria crítica da tecnologia de Andrew Feenberg. Esse conceito se alinha aos nossos interesses de investigação porque permite reconhecer o entrelaçamento entre escolhas sociais e técnicas nos projetos (designs) de artefatos e sistemas. A primeira parte desse texto contém uma breve apresentação das concepções da teoria crítica da tecnologia e busca mostrar de que maneira elas permitem pensar nosso objeto de pesquisa. Assim, por meio desses conceitos, discutiremos fragmentos da história do design do sistema de transporte curitibano, iniciando com o Plano Diretor da década de 1960, passando pelas transformações que sofreu no cotidiano até o final da década de 1980 . Finalizamos o texto com uma discussão das possibilidades e impossibilidades da participação popular na construção social da tecnologia tensionando a dicotomia entre projeto e uso.

\section{CÓDIGOS TÉCNICOS NO TRANSPORTE COLETIVO CURITIBANO}

O esforço para pensar histórias de designs a partir dos Estudos de Ciência, Tecnologia e Sociedade tem permitido deslocar o foco centrado na figura do designer para uma visão mais ampliada, considerando outros atores e/ou grupos sociais que dão forma aos sistemas e artefatos em processos permeados por relações de poder. Segundo Feng e Feenberg (2008), esse quadro teórico-metodológico concebe o design como um "processo pelo qual considerações sociais e técnicas convergem para produzir dispositivos concretos adequados a contextos específicos". Para eles, o ponto crucial para as pesquisas dentro dessa abordagem é entender como isso acontece e a possibilidade de acontecer de outras maneiras.

A história do transporte coletivo na cidade de Curitiba envolve a construção social de um sistema técnico no tempo. Seu design foi concebido num contexto político, cultural e socioeconômico que permitiu certas configurações enquanto constrangeu outras. Devemos pensar esse contexto como dinâmico, assim como são dinâmicas as negociações entre diferentes grupos sociais - organizados ou não - que contribuíram para a definição do desenho do transporte coletivo. Esse desenho adquiriu seus contornos mais visíveis na década de 1970, quando foi fortemente vinculado ao uso do solo e sistema viário de um novo Plano Diretor (PD). O PD buscou orientar o crescimento da cidade em dois sentidos: norte-sul e leste-oeste, por meio de eixos que tangenciavam o centro e pelos quais circulam as linhas de ônibus "expresso" ${ }^{1}$

\footnotetext{
${ }^{1} \mathrm{O}$ "Expresso" é uma linha de ônibus que opera em via exclusiva no sentido linear, levando passageiros nos sentidos centro/bairros e bairros/centro, esse tipo de sistema também é conhecido pela sigla BRT
} 
(Figura 1 ).

O Plano Preliminar de Urbanismo (PPU) de Curitiba, que deu origem ao PD, foi elaborado por uma sociedade entre empresas de engenharia e arquitetura paulistas, a Serete, e um grupo local de acompanhamento. Em 1966 o PD foi transformado em projeto de lei e, em 1974, o novo sistema de transporte começou a ser implantado, quando a cidade estava sob a gestão do arquiteto e urbanista Jaime Lerner e da equipe técnica do Ippuc (IPPUC, 1966; OLIVEIRA, 2000; SOUZA, 1999). Os corredores de transporte por onde passavam os expressos receberam, anos depois, alguns terminais de integração que difundiam as linhas alimentadoras para o interior dos bairros. Além dessas, foram incluídas no sistema as linhas troncais e convencionais - que vão dos terminais e bairros para o centro; e linhas circulares, que fazem o trajeto entre bairros (Interbairros) ou circulam pelo centro.

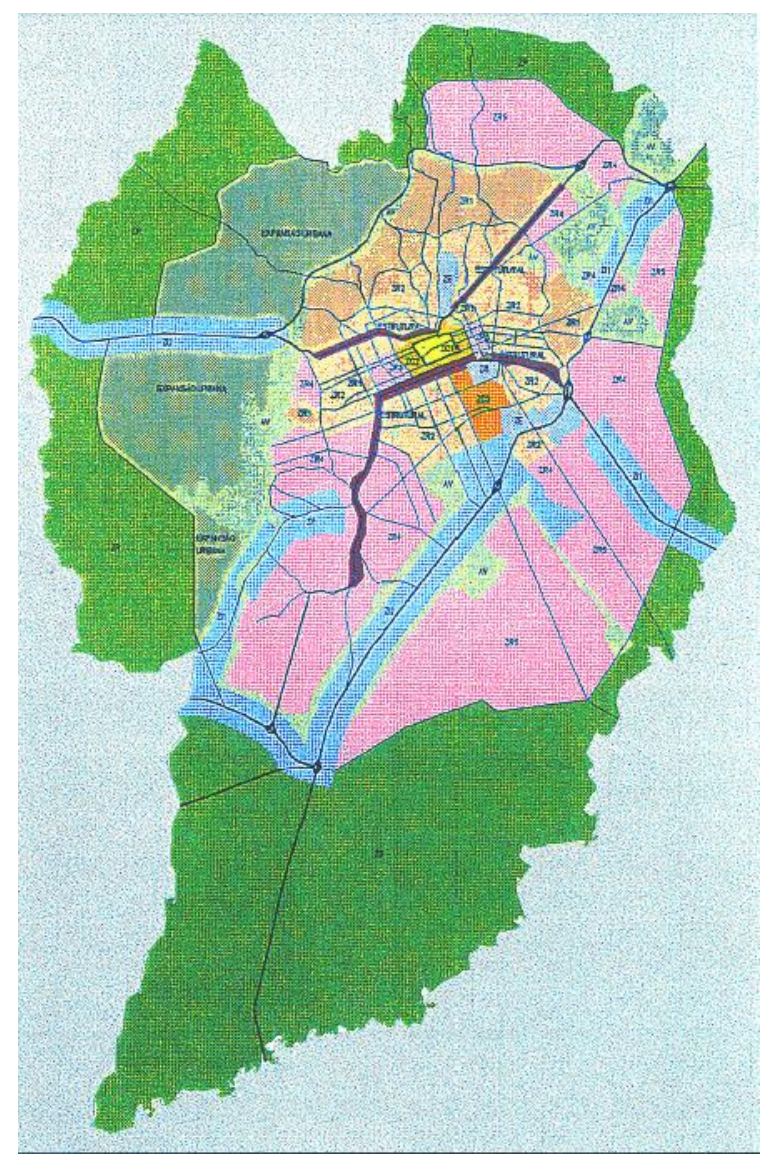

Figura 1 - Mapa de Curitiba com destaque para os dois eixos estruturais (em marrom) e zoneamento previstos pelo Plano Diretor. Fonte: IPPUC, 1966.

Mesmo que o planejamento fosse da equipe técnica da prefeitura, a operação do sistema de transporte curitibano sempre aconteceu, de forma mais ou menos regulada, por empresas privadas (OLIVEIRA, 2000; NEVES, 2006). As abordagens construtivistas produzidas o interior dos Estudos Sociais em Ciência e Tecnologia permitem perceber que a tecnologia é moldada no sentido de privilegiar os interesses dos grupos que participam da sua construção (BIJKER, 1997). Assim, podemos perceber o design do transporte urbano em Curitiba enviesado na direção da conveniência 
desses grupos oficiais de urbanistas, técnicos, engenheiros e gestores da prefeitura e empresas de transporte, sem excluir a pressão de outros e a tensão entre esses. 0 projeto e implantação aconteceram em um contexto político, social e econômico marcado pela ditadura militar, no qual a orientação tecnoburocrática esteve alinhada à execução e implantação de políticas públicas de forma autoritária (NEVES, 2006, p.101). O golpe também permitiu que o empresariado fosse beneficiado na operação do transporte público. De acordo com Urban (1986, p.42), "as empresas cresceram, sempre com o apoio das instituições do governo, que lhes asseguravam um privilegiado sistema de planejamento, com vias exclusivas e custos reduzidos".

O ponto de interseção entre as escolhas sociais e as especificações técnicas, ou melhor, a tradução das primeiras nas segundas, é chamado por Feenberg (2011) de Código Técnico. Essa tradução ou sedimentação de valores e interesses pode tanto acontecer em artefatos particulares, como um ônibus; em regras e procedimentos, como a operação das linhas ou o regime de trabalho de motoristas; ou mesmo em domínios técnicos inteiros. Com a noção de código técnico, esse autor procura mostrar que existem várias soluções diferentes para um problema técnico. Na adoção de uma visão determinista e instrumentalista da tecnologia, é a busca pela "eficiência" que definirá a escolha de certa configuração para um sistema técnico. Esse olhar mais estreito tem sido contestado tanto pelos movimentos sociais quanto pelos estudos contemporâneos da tecnologia, na proposta de que outros fatores além da eficiência são preponderantes para a escolha do design (FEENBERG, 2002, p.15).

Podemos observar processos de incorporação e representação da "eficiência", tanto no projeto do sistema de transporte como no design dos veículos e mobiliário do transporte coletivo. O ônibus expresso, por exemplo, implantado nos dois corredores de transporte dos eixos estruturais em 1974, era muito diferente dos veículos de transporte coletivo urbano da época. O aspecto visual envolvia linhas retas, cor vibrante e uso extenso do vidro. A circulação no seu interior foi planejada no sentido de agilizar o embarque e desembarque. Além disso, o layout de assentos longitudinais permitia aumentar o espaço para passageiros em pé e, consequentemente, o número de passageiros (100 pessoas) por carro (TOMIZAWA, 2013; URBS, 1998). Outro aspecto destacado pelos projetistas do primeiro expresso era a preocupação com o controle e a segurança, traduzida na visibilidade entre passageiros, motorista e cobrador. A posição das portas de entrada, por exemplo, foi modificada de modo que o motorista pudesse ver o usuário subir pela parte dianteira do carro (TOMIZAWA, 2013). O controle também era importante no sentido de garantir o pagamento da tarifa: no interior do ônibus, havia uma área na parte frontal anterior ao cobrador e uma área que só era acessada com o pagamento da passagem, na parte posterior do veículo, onde a porta de saída estava localizada (Figura 2).

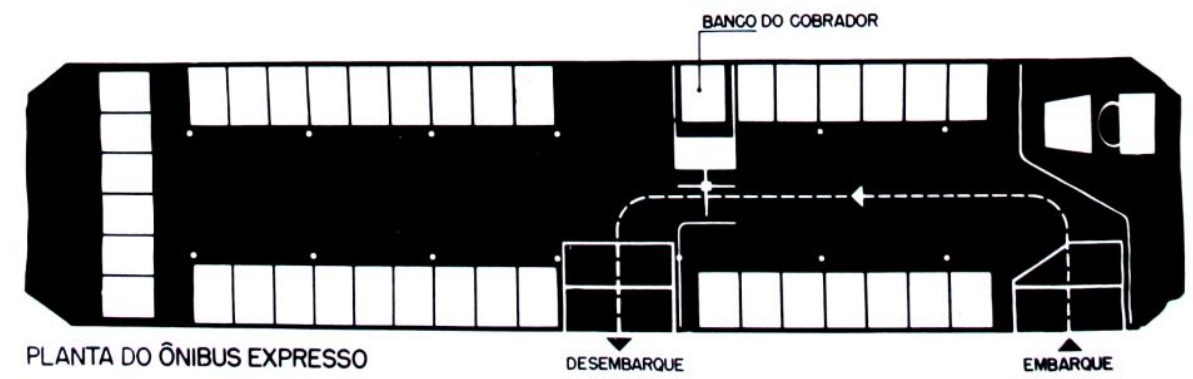


Figura 2 - Planta do ônibus expresso em impresso de divulgação da prefeitura. Fonte: DEPARTAMENTO DE RELAÇÕES PÚBLICAS E PROMOÇOES DA PREFEITURA MUNICIPAL DE CURITIBA, 1974.

O sistema de transporte foi ganhando maior complexidade com o passar do tempo, no acréscimo de linhas, trajetos e equipamentos. Em 1977, um novo corredor de ônibus expresso foi incluído na rede, ligando o bairro Boqueirão à região central. Esse eixo já tinha sido previsto pelo plano alternativo ao PD oficial, nas discussões que ocorreram na década de $1960^{2}$. Podemos interpretar esse "desvio" do projeto Serete como inclusão de uma demanda social a qual os projetistas locais teriam sido mais sensíveis (IPPUC, 1990, 1991). Em 1979, entra em operação o ônibus Interbairros, com sua primeira linha conectando os terminais de três bairros (URBS, 1998) e, em 1980, mais um trecho do ônibus expresso é implantado na região leste da cidade.

No início de 1980 foi criada uma comissão de estudo para implantação de uma tarifa única para o sistema. A comissão foi constituída pela prefeitura, um vereador e um representante do sindicado das empresas de transporte. A "tarifa social" foi implantada três meses depois, vinculada à integração dos ônibus que passavam pelos terminais ${ }^{3}$ (CURITIBA, 1980; 1980a). Nessa configuração, as linhas de trajetos menores subsidiavam o custo que as empresas teriam com as linhas que percorriam maiores distâncias. É importante destacar que, nessa época, as empresas operavam em áreas prioritárias pré-definidas, que mesclavam trechos mais lucrativos com outros de menor fluxo de passageiros (CURITIBA, 1981). Outra mudança que afetou a qualidade do transporte no período foi a renovação do contrato entre a prefeitura e empresas por dez anos e a prorrogação da vida útil dos ônibus, de cinco para oito anos, período no qual as empresas eram remuneradas pela "depreciação" do veículo (NEVES, 2006).

A exclusão de setores populares desse tipo de decisão mostra como se dava a gestão do transporte durante a administração do prefeito indicado Jaime Lerner, alinhado à concepção tecnocrática do governo militar. Além disso, é possível notar como as políticas de transporte definidas nesse contexto implicavam materialmente no uso dos ônibus, fosse na existência de terminais fechados, condicionados ao pagamento da tarifa, ou na precariedade dos veículos. O trabalho de Souza (1999) mostra que até a instalação dos terminais (quase sete anos após a inauguração do expresso) foi usada uma solução provisória, uma espécie de "gaiola" com cerca de 10 metros quadrados em grade aramada, onde os passageiros ficavam fechados aguardando a baldeação (SOUZA, 1999, p.283).

O período entre o final da década de 1970 e início da década de 1980 assistiu à emergência dos movimentos sociais e a luta pela redemocratização do país. Na fase final da ditadura militar, como destacam Oliveira (2000) e Neves (2006), os movimentos populares e sindicatos urbanos buscaram se organizar no sentido de exercer maior influência nas políticas de transporte coletivo e habitação. Em 1983 chegam ao poder, no governo do Paraná e na prefeitura de Curitiba, José Richa e Maurício Fruet, ambos do PMDB, partido de oposição ao regime militar. O primeiro prefeito eleito após a ditadura foi Roberto Requião, também do PMDB, que como deputado estadual já

2 Essas discussões teriam ocorrido na consulta aos arquitetos locais e durante a apresentação do plano em um seminário que foi chamado de "Curitiba de Amanhã" (IPPUC, 1990, 1991; OLIVEIRA, 2000).

${ }^{3}$ A tarifa única era cobrada somente no acesso às linhas Convencional e Expresso pelos terminais. As linhas "seletivas", (rebatizadas de "opcionais") que operavam em bairros de maior concentração de renda, chegavam a custar o dobro da tarifa convencional (CURITIBA, 1980b) 
denunciava e buscava investigar o poder das empresas no sistema de transporte curitibano (NEVES, 2006). Durante a gestão de Maurício Fruet, no ano de 1984, foi criada a Comissão de Verificação de Custos, da qual participavam três organizações do movimento popular. De acordo com o decreto no 254, ela teria o objetivo de "proceder o exame da escrituração contábil e mercantil das Empresas Contratadas do Serviço Público de Transporte Coletivo de Passageiros" (CURITIBA, 1984). A constatação de diversas irregularidades e a publicação de um relatório por essa comissão contribuiu para ampliar o controle do sistema pela população. Nessa época, a prefeitura chegou a autorizar a contratação de representantes dos movimentos populares como fiscais do transporte coletivo e a incluir essas entidades no Conselho Municipal de Transportes no ano seguinte (NEVES, 2006, p.160). Em 1986, Roberto Requião assume a prefeitura e encomenda um parecer jurídico sobre a nulidade dos contratos prorrogados com as empresas em 1981. Em 1987, a partir desse parecer, o prefeito baixa um decreto anulando as concessões e outro com novo regulamento para o transporte coletivo, (CURITIBA, 1987, 1987a). Com os decretos, a remuneração passou a ser por quilômetro rodado e a arrecadação controlada pelo município, parte dela empregada para a aquisição de uma frota pública.

\section{PARTICIPAÇÃO POPULAR NO DESIGN DA TECNOLOGIA URBANA}

Conforme apresentamos no item anterior, poucas foram as oportunidades oficiais de participação popular no design do transporte coletivo na cidade de Curitiba. A teoria crítica da tecnologia trabalha com a ideia de que aquelas pessoas que detém o controle da tecnologia possuem, por conseguinte, maior poder de decisão sobre o desenho das cidades, das habitações e dos sistemas de transporte, ou mesmo de "nossa experiência como empregados, pacientes e consumidores do que o conjunto de todas as instituições governamentais de nossa sociedade" (FEENBERG, 2010, p.69). Assim, as escolhas técnicas nunca são neutras no sentido em que são tomadas com determinados interesses e objetivos em contextos específicos. A sua eficiência é medida no sentido em que cumprem os objetivos daqueles/as que definem seu design. No caso de um sistema de uso público, como o transporte coletivo, ele deixa de ser eficiente para a população urbana quando é projetado em função de demandas particulares.

Com o objetivo de considerar com maior ênfase aqueles e aquelas que não foram convidados/as a participar do desenho tecnológico do transporte coletivo em Curitiba, discutiremos algumas estratégias adotadas no sentido de fazer valer as demandas populares. Por meio de fragmentos de reportagens jornalísticas, mostraremos algumas das contradições do ônibus expresso a partir de sua implantação em 1974. Como já apontamos na primeira parte deste artigo, a ascensão dos movimentos sociais urbanos entre o final da década de 1970 e início da década de 1980 tornou possível uma maior participação da população nas decisões sobre o transporte. A pressão do movimento popular fez com que algumas decisões fossem tomadas no campo das políticas de transporte que, consequentemente, alteraram parcialmente e momentaneamente - o código técnico incorporado por esse sistema.

\subsection{Usos do ônibus expresso}

Entre os dias 17 e 28 de setembro de 1974, todas as edições do jornal Gazeta do Povo comentavam o "ônibus expresso" e sua inauguração em 22 de setembro. 0 jornal 
noticiava a ansiedade e as desconfianças da população quanto ao novo sistema e chegou até mesmo a especular a existência de veículos equipados com calefação para os dias frios e ar refrigerado para os dias quentes, além da possibilidade de todos os passageiros viajarem sentados (MUITA, 1974; EXPRESSO, 1974). Com a criação do sistema expresso, circulando pelos eixos estruturais, também se esperava que os habitantes motorizados da cidade deixassem seus automóveis em favor do transporte de massa. Passado um mês e meio da inauguração do expresso, a quantidade de pessoas que possuíam carro, mas utilizava o ônibus correspondia a 17,6\% do total de usuários, de acordo com levantamento realizado pelo IPPUC (IPPUC, 1975). Outra pesquisa, realizada em 1979 por um instituto de opinião pública, revelou que o principal meio de transporte da cidade era o ônibus. Entre as pessoas entrevistadas, $93 \%$ das pertencentes à classe $\mathrm{C}$ e $95 \%$ à classe $\mathrm{D}$ eram usuários do transporte coletivo, enquanto $86 \%$ das pertencentes à classe $A$ e $44 \%$ da classe $B$ utilizavam carro próprio ou da família para locomoção (INSTITUTO, 1979). Assim, as pessoas mais pobres constituíam a maioria dos usuários do sistema.

As dificuldades que surgiriam no uso dos ônibus expressos foram por vezes documentadas pela imprensa. Após a inauguração, a contradição: enquanto o jornal noticiava atropelamentos, acidentes e longas filas de espera, também mostrava que os ônibus comuns que circulavam na via exclusiva passaram a ser rejeitados pela população em favor do expresso (ONIBUS, 1974; EXPRESSO, 1974a). Os diversos acidentes ocorridos com o novo ônibus acabaram the rendendo o apelido de "Diabo Vermelho" (LAUFER, 2004; TOMIZAWA, 2013). Ainda na primeira semana de uso, outras reclamações de usuários ressoaram na imprensa, como a lotação dos veículos nos horários de pico e a altura dos corrimões e alças para acionamento da campainha, inalcançáveis às pessoas de baixa estatura (CONFUSÃO, 1974). Dez dias após a inauguração do veículo, uma carta de leitor com o título "Desconforto" foi publicada pelo jornal. Nela, ele elogia a beleza dos novos ônibus, mas faz uma crítica ao afirmar que "o povo é obrigado a viajar em pé, ou então sentados nos duros bancos de fibra de vidro" (WERSHOSKI, 1974). Segundo levantamento supracitado, dois meses após a inauguração do ônibus, quase metade dos passageiros entrevistados $(49,2 \%)$ consideraram os bancos inadequados (IPPUC, 1975). Até mesmo um arquiteto e urbanista do Ippuc, em depoimento na década de 1990, afirma que "os bancos deveriam ser estofados (...)" e que "o banco de fibra não é muito quente e em Curitiba faz muito frio" (IPPUC, 1991). Para Souza (1999, p.270), os projetistas estariam conscientes do desconforto causado pelo novo assento, mas optaram pela limpeza. Contudo, outras estratégias foram tomadas para associar o veículo ao conforto, como a música interna, a redução do tempo de percurso e a própria limpeza ${ }^{4}$.

$\mathrm{O}$ atendimento a algumas dessas demandas viria com o tempo, como o aumento no número de veículos e a redução da velocidade para evitar acidentes (VINDA, 1974). Apesar disso, as críticas ao sistema foram frequentes, chegando a fazer

4 Souza (1999 p.270) cita estudo do Ippuc produzido em 1974 com a seguinte colocação: "Assentos de plástico moldado seriam mais fáceis de limpar, porém é improvável que dessem maior conforto ao passageiro (...)." O mesmo estudo mostra que a insistência nos assentos de plástico foi estimulada pelo fato do ônibus Expresso circular por "vias bem pavimentadas" que não causariam vibrações nos assentos. Até o momento, nossa pesquisa não identificou as razões pelas quais outras linhas fora da via exclusiva passaram a receber assentos em fibra enquanto se manteve o estofado nas linhas Seletivas (notas 3 e 5 ). 
parte da memória dos projetistas do IPPUC em tempos mais recentes. O arquiteto e urbanista Rafael Dely, em 2004, comentou que "o ônibus era chamado de Joaquim Américo [estádio do Clube Atlético Paranaense]: cinco pessoas sentavam e o resto ficava em pé!" (LAUFER, 2004). A revista mensal Paraná em Páginas, que frequentemente denunciava o prefeito da época, publicou um dossiê no mês de novembro de 1974 com o seguinte título: "Expresso: monstro que Lerner criou". A página que abre a matéria foi ocupada com quatro fotografias de veículos amassados ou parados por acidentes na via exclusiva por onde o expresso circulava. Sobre o design interno do veículo, na página seguinte, o comentário: "É de construção que apresenta falhas gritantes, como por exemplo, o ' cano' para que os passageiros que ficam em pé nele se agarrem. $O$ cano está colocado em altura que não permite a qualquer um segurá-lo." Os bancos também foram alvo de crítica, chamados de "verdadeiro 'toco duro'" (EXPRESSO, 1974b).

A partir desse apanhado, foi possível compreender como as pessoas envolvidas com essa tecnologia atribuíram significados a experiência - ao mesmo tempo, assustadora e encantadora - de interagir com o sistema de transporte curitibano. Os apelidos e protestos também contribuem para o desvelamento de um sistema aparentemente democrático, pois o conforto não era para todos/as ${ }^{5}$. A demanda pelo transporte coletivo na cidade correspondia às pessoas mais pobres, pois as poucas que possuíam automóveis faziam uso dele para a locomoção (IPPUC, 1986).

\subsection{A luta pelo transporte na década de 1980}

Como foi colocado na primeira parte deste artigo, a ascensão dos movimentos que levaram à abertura política, tornou mais forte e visível o trabalho das associações de bairros, na sua luta por condições moradia e acesso ao transporte. Souza (1999), em trabalho sobre o planejamento urbano de Curitiba, aponta a atuação do movimento popular em duas frentes ligadas ao transporte, a primeira voltada para a obtenção de gratuidade do ônibus para os trabalhadores desempregados e o congelamento das tarifas por tempo indeterminado. A segunda frente buscava a "revisão total da metodologia empregada pela planilha, colocando em dúvida os dados nos quais se baseavam as empresas para reivindicarem reajustes de preços das passagens". Outra proposta do movimento popular destacada por Oliveira (2000) e que ecoou nas medidas tomadas pelo prefeito Roberto Requião, em 1987, foi a estatização do serviço de ônibus por meio da criação de uma frota pública.

Assim, a pressão popular tornou possível algumas transformações no sistema de transporte, com vistas a diminuir o poder do empresariado e aumentar o controle do poder público. As mudanças envolveram a anulação dos contratos de concessão e a elaboração de contratos de permissão, o fim das áreas seletivas - que prejudicava o atendimento nas áreas não priorizadas pelas empresas -, o início da remuneração por quilômetro e a diminuição da vida útil dos veículos (CURITIBA, 1987a). O controle das receitas do transporte também permitiu a criação de um fundo para a aquisição da frota pública, que além de operar segundo critérios de uso e menor custo, sem objetivos de lucro, ainda permitia "estabelecer padrões de controle, gastos e manutenção que serão permanentemente comparados com os custos apresentados

\footnotetext{
${ }^{5}$ Os ônibus Seletivos ou Opcionais, já citados na nota 3 e 4, possuíam capacidade para 19 passageiros sentados em bancos estofados. A linha foi projetada para incentivar as pessoas de maior poder aquisitivo a tomar o ônibus em lugar do automóvel particular (IPPUC, 1986; TOMIZAWA, 2013).
} 
pelas empresas privadas" (URBAN, 1987). Contudo, Neves (2006) aponta que a gestão de Requião, entre 1986 e 1989, teria sido um retrocesso em relação à prefeitura de Maurício Fruet no que tange à participação popular. Segundo esse autor, o papel do Conselho Municipal teria perdido sua importância e as decisões sobre tarifa passaram a ser tomadas de forma autoritária. Em janeiro de 1989, Jaime Lerner volta ao cargo de prefeito democraticamente e reformula o Conselho, acabando com a participação popular. Nessa época, uma medida judicial iniciada pelos empresários encerrou com a frota pública além de reajustar a tarifa em favor desses (NEVES, 2006, p.168-169).

\section{CONSIDERAÇÕES FINAIS}

A partir dessa revisão fragmentária da história do transporte na cidade de Curitiba, à luz da teoria crítica da tecnologia, buscamos mostrar de que maneira as questões sociais se entrelaçam ao design da tecnologia. É a partir do conceito de código técnico que propusemos uma discussão dos atores que forjaram o sistema de transporte curitibano em um momento histórico específico, que privilegiou algumas configurações em detrimento de outras. No entanto, as possibilidades desse sistema ser diferente apareceram em diversos momentos e situações no decorrer da história, como procuramos evidenciar nos recortes jornalísticos sobre o uso cotidiano do sistema e nas intervenções com vistas à maior participação pública no sistema de transporte. Apesar disso, percebemos que poucas foram as mudanças na configuração material do sistema, como o desenho dos ônibus, das vias e terminais, que, como apontamos, levaram em conta os critérios de eficiência dentro de uma visão instrumentalista da tecnologia. Segundo Feenberg (2011) "quando um código técnico é bem estabelecido, as abordagens alternativas que ele exclui são esquecidas. Um tipo de inconsciência cobre a história anterior e obscurece a imaginação de alternativas futuras" ${ }^{\prime \prime}$ (FEENBERG, 2011, p.8, tradução da autora). Assim, é importante para os estudos críticos da história da tecnologia destacar a existência de designs alternativos ao estabelecido, mostrando a possibilidade de incorporar outros valores aos sistemas técnicos.

A partir dos exemplos que abordamos brevemente nesse trabalho, foi possível enfatizar a riqueza dos pontos de vista daqueles e daquelas que usam, ou são excluídos do uso dessa tecnologia em relação aos que a administram. No caso do transporte público, as pessoas passageiras e os/as trabalhadores/as do sistema não concebem o sistema em termos de eficiência instrumental e de controle, mas em função das possibilidades que oferece para promover encontros e deslocamentos na cidade. A inserção dessas massas de indivíduos no interior dos sistemas técnicos seria o caminho vislumbrado na conquista de uma sociedade mais humanizada e igualitária. Somente a participação das pessoas envolvidas numa tecnologia permitiria a transformação do desenho tecnológico para permitir outros modos de vida. Nesse trabalho, buscamos investigar alguns espaços de manifestação [mediada] das demandas populares. $\mathrm{Na}$ contribuição da teoria crítica para pensar o transporte público na cidade de Curitiba, percebemos a tecnologia como "um processo 'ambivalente' de desenvolvimento suspenso entre diferentes possibilidades. (...) Nesta visão, a tecnologia não é um destino, mas um 'parlamento de coisas' dentro do qual as alternativas de civilização

\footnotetext{
${ }^{6}$ When a technical code is well-established the alternative approaches that it excludes are forgotten. A kind of technological unconsciousness covers over the earlier history and obscures the imagination of future alternatives.
} 
competem" (FEENBERG, 2002, p.11).

\section{REFERÊNCIAS}

BIJKER, Wiebe. Of Bicycles, Bakelites, and Bulbs: Toward a Theory of Sociotechnical Change. London: MIT Press, 1997.

CONFUSÃO no primeiro dia do expresso. Gazeta do Povo, Curitiba, p.1, 24 set. 1974.

CURITIBA. Decreto Municipal n. 92 de 30 de janeiro de 1980. Curitiba: Palácio 29 de Março, 1980. Disponível em: <http://cm-curitiba.jusbrasil.com.br>. Acesso em: 20 abril 2014.

CURITIBA. Decreto Municipal n. 400 de 25 de abril de 1980. Curitiba: Palácio 29 de Março, 1980a. Disponível em: <http://cm-curitiba.jusbrasil.com.br>. Acesso em: 20 abril 2014.

CURITIBA. Decreto Municipal n. 768 de 17 de julho de 1980. Curitiba: Palácio 29 de Março, 1980b. Disponível em: <http://cm-curitiba.jusbrasil.com.br>. Acesso em: 20 abril 2014.

CURITIBA. Decreto Municipal n. 404 de 19 de novembro de 1981. Curitiba: Palácio 29 de Março, 1981. Disponível em: <http://cm-curitiba.jusbrasil.com.br>. Acesso em: 20 abril 2014.

CURITIBA. Decreto Municipal n. 254 de 14 de agosto de 1984. Curitiba: Palácio 29 de Março, 1984. Disponível em: <http://cm-curitiba.jusbrasil.com.br>. Acesso em: 20 abril 2014.

CURITIBA. Decreto Municipal n. 44 de 30 de janeiro de 1987. Curitiba: Palácio 29 de Março, 1987. Disponível em: <http://cm-curitiba.jusbrasil.com.br>. Acesso em: 20 abril 2014.

CURITIBA. Decreto Municipal n. 45 de 30 de janeiro de 1987. Curitiba: Palácio 29 de Março, 1987a. Disponível em: <http://cm-curitiba.jusbrasil.com.br>. Acesso em: 20 abril 2014.

DEPARTAMENTO DE RELAÇÕES PÚBLICAS E PROMOÇOES DA PREFEITURA MUNICIPAL DE CURITIBA. Roteiro da Cidade. n.9. Junho de 1974.

EXPRESSO funciona no domingo. Gazeta do Povo, Curitiba, p.28, 18 set. 1974.

EXPRESSO e seus inúmeros casos. Gazeta do Povo, Curitiba, p.6, 29 set. 1974a.

EXPRESSO: Monstro que Lerner Criou. Paraná em Páginas, v.10, n.117. Curitiba:

Editora Jornalística Paraná em Páginas, nov. 1974b.

FEENBERG, Andrew. As Variedades de Teoria. Tecnologia e o Fim da História. In: Transforming Technology. A Critical Theory Revisited. New York: Oxford University Press, 2002, pp. 3-35. Tradução: Carlos Alberto John. Disponível em:

http://www.sfu.ca/ andrewf/books/Portug_Chapter_1_Transforming_Technology.pdf . Acesso em: janeiro 2014. 
Agency and Citizenship in a Technological Society. Palestra apresentada no curso de Cidadania Digital, University of Copenhagen, 2011. Disponível em: http://www.sfu.ca/ andrewf/copen5-1.pdf. Acesso em: 26 novembro 2013.

Racionalização Subversiva: Tecnologia, Poder e Democracia. Tradução de Anthony T. Gonçalves. In: NEDER, Ricardo T. (org.). A teoria crítica de Andrew Feenberg: racionalização democrática, poder e tecnologia. Brasília: Observatório do Movimento pela Tecnologia Social na América Latina / CDS / UnB / Capes, 2010. p.6995.

FENG, P.; FEENBERG, A. Thinking About Design: Critical Theory of Technology and the Design Process. In: VERMAAS, P. E. et al. (eds.). Philosophy and Design: From Engineering to Architecture. New York: Springer, 2008. p.104-118.

INSTITUTO GALLUP DE OPINIAO PÚBLICA. Relatório dos trabalhos de pesquisa sobre Problemas de Transportes Urbanos em Curitiba. Curitiba: IPPUC, 1979.

IPPUC. Plano Diretor: Anteprojeto de Lei. Maio, 1966. Disponível em: <http://www.ippuc.org.br>. Acesso em: 05 ago 2013.

Avaliação da opinião pública em relação à implantação do sistemas de ônibus expresso em Curitiba. Curitiba: IPPUC, 1975.

Sistema de Transporte Coletivo de Curitiba: peculiaridades, soluções locais.

Curitiba: IPPUC, 1986.

Memória da Curitiba Urbana: planejamento urbano: concepção \& prática.

Curitiba, PR: IPPUC, 1990. (Depoimentos, 5)

Memória da Curitiba Urbana: planejamento urbano: concepção \& prática.

Curitiba, PR: IPPUC, 1991. (Depoimentos, 7)

LAUFER, Felipe. Expresso, ex-“Diabo Vermelho", faz 30 anos. Gazeta do Povo. Curitiba, p.5, 14 nov. 2004.

MUITA coisa por fazer nas obras do expresso. Gazeta do Povo, Curitiba, p.1, 17 set. 1974.

NEVES, Lafaiete Santos. Movimento popular e transporte coletivo em Curitiba (19701990). Curitiba: Editora Gráfica Popular: CEFURIA, 2006.

OLIVEIRA, Dennison de. Curitiba e o mito da cidade modelo. Curitiba: Ed. da UFPR, 2000.

ÔNIBUS comum agora é rejeitado. Gazeta do Povo, Curitiba, p.1, 27 set. 1974.

SOUZA, Nelson Rosario de. Planejamento urbano, saber e poder: o governo do espaço e da população em Curitiba. 1999. 316f. Tese (doutorado) - Universidade de São Paulo, Faculdade de Filosofia, Letras e Ciências Humanas.

TOMIZAWA, L. T Entrevista concedida a Suelen Caviquiolo. Curitiba, 13 de agosto de 2013, 1 hora de duração.

URBAN, Teresa. Transporte Coletivo. Curitiba: Prefeitura Municipal de Curitiba, 1987.

URBS. Transporte Coletivo Curitiba e Região Metropolitana: A história, o planejamento urbano e a evolução do Sistema Integrado. Curitiba, URBS: 1998. 
WERSHOSKI, A. Desconforto. Gazeta do Povo, Curitiba, 2 out. 1974, Coluna do Leitor, p.6. 